\title{
Influence of Plasma and Cold Spray Deposited Ti Layers on High-Cycle Fatigue Properties of Ti6Al4V Substrates
}

\author{
${\text { Jan } \text { Cizek }^{\mathrm{a}, *} \text {, Ondrej Kovarik }}^{\mathrm{b}}$, Jan Siegl ${ }^{\mathrm{b}}$, Khiam Aik Khor ${ }^{\mathrm{c}}$, Ivo Dlouhy ${ }^{\mathrm{a}}$ \\ ${ }^{a}$ Institute of Materials Science and Engineering \\ Faculty of Mechanical Engineering \\ Brno University of Technology, Czech Republic \\ ${ }^{b}$ Department of Materials \\ Faculty of Nuclear Sciences and Physical Engineering \\ Czech Technical University in Prague, Czech Republic \\ ${ }^{c}$ School of Mechanical and Aerospace Engineering \\ Nanyang Technological University, Singapore
}

(C) 2013. This manuscript version is made available under the CC-BY-NC-ND 4.0 license

(http://creativecommons.org/licenses/by-nc-nd/4.0/)

doi:10.1016/j.surfcoat.2012.11.067

Final version available from

http://www.sciencedirect.com/science/article/pii/S0257897212012200

\begin{abstract}
This paper presents a summary of the research on the influence of plasma and cold spray deposition of bio-grade Ti powder on the high-cycle fatigue properties of Ti6Al4V substrates.

Four sets of flat specimens (as-received, grit-blasted, plasma and cold sprayed) were prepared and subjected to cantilever-beam cyclic bend loading with a constant deflection of the free end.

It was found that the grit-blasting procedure significantly increased the fatigue lives of the specimens as compared to the as-received set $(1.81 \times$ increase). The deposition of the coatings onto grit-blasted specimens led to a deterioration of the increase: the average fatigue lives of the plasma sprayed and cold sprayed sets reached $1.16 \times$ and $0.91 \times$ of the live of as-received specimens, respectively.

In order to understand the positive effect of the grit-blasting procedure and the adverse effect of the coatings deposition on fatigue lives, chemical analyses, fractographic analysis, microstructural investigations as well as layers elastic moduli estimation were carried out. It was found that the cold spray deposition retained the composition of the powder feedstock while a complete transformation of Ti into nitrides and oxides was detected in the plasma deposited layers. Owing to the different coating build-up principles and their respective different porosity levels, the moduli of the coatings were found to vary (7.2 GPa for plasma sprayed and $36.7 \mathrm{GPa}$ for cold sprayed layers). The fatigue cracks initiation sites and propagation directions in the plasma and cold sprayed specimens were found to differ substantially. Based on the obtained results and the internal stresses analysis, two explanations of the fatigue loading results are suggested in the paper.
\end{abstract}

Keywords: cold spray, plasma spray, high-cycle fatigue, Ti6Al4V, titanium coating, internal stresses, elastic moduli calculation

\section{Introduction}

Owing to the combination of its mechanical properties (density vs. toughness), corrosion resistance properties and its in-vivo non-toxicity, titanium has been long proven as an excellent biocompatible material [1]. It is particularly suitable in joint and hard tissue replacements or fracture fixations due to its osseointegration abilities. Apart from pure titanium, Ti6Al4V alloy has gained a special importance

\footnotetext{
${ }^{*}$ Corresponding author

Email address: cizek@fme.vutbr.cz (Jan Cizek)
} 
in the case of bone and joint replacements recently: it is a chemically stable biocompatible substrate with relatively low elastic modulus and excellent corrosion resistance able to carry mechanical load [2]. Likewise, Ti6Al4V implants do not induce allergic reactions.

Thermal spray methods have been traditionally used for deposition of protective or bio-compatible coatings onto prepared components (bone implants, synovial joints) [3]. Among these deposition technologies, the attention has been mainly focused on plasma spraying due to its versatility, ability to deposit thick coatings onto extensive batches of components, its reliability, relative ease of operation and low production cost [4]. In plasma spraying, the deposited material is inserted into a plasma jet (usually generated by an electric arc passing through a flow of gases which become ionized) and propelled towards a substrate at typical speeds between $100 \mathrm{~m} \cdot \mathrm{s}^{-1}-600 \mathrm{~m} \cdot \mathrm{s}^{-1}$. During their short dwelling time in the jet, the particles of the material partially or fully melt due to an immense heat input from the plasma jet (generated by a re-combination of the ionized gases), undergo a severe deformation upon impact at the prepared substrate material a re-solidify. The final coatings consist of layers of these solidified particles ("splats") deposited by successive passes of the plasma gun over the substrate.

Despite the unquestionable advantages of plasma spraying, the principle of the technology entails several inherent issues frequently encountered in the production process, e.g. phase and structural changes, oxidation, selective evaporation and chemical decompositions of the materials and residual stresses buildup [4]. The residual stresses in the coated specimens could be divided into two classes [5]: primary ("quenching") stresses develop immediately after impingement of a particle as a result of fast thermal contraction of solidifying splats. As the molten particles solidify they contract, but are constrained by each other and the substrate, generating stresses of a tensile nature. Secondary ("thermal") stresses arise from the mismatch in thermal contractions of a substrate and a coating upon cooling to ambient temperature. Their magnitude is a function of the coating thickness and their nature could be either tensile or compressive. The overall residual stress field originates from a combination of the two stresses and is frequently alleviated by the introduction of vertical cracking of the coating material or debonding from the substrate.

Cold spraying is an incoming surface treatment technology [6] eliminating some of these issues. In cold spray, a compressed gas such as helium, nitrogen or purified air is introduced to an electric furnace (pressure gas) and a powder feeder (feeder gas). The pressure gas is moderately heated (generally

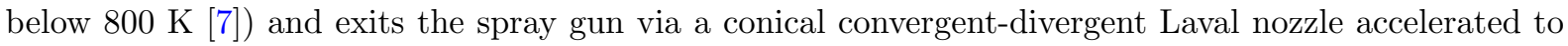
supersonic velocities [6]. Feedstock powder is injected into the gas flow and accelerated to velocities of $300 \mathrm{~m} \cdot \mathrm{s}^{-1}-1200 \mathrm{~ms}^{-1}$. Contrary to its high-temperature counterparts, cold sprayed coatings are built by means of solid-state plastic deformation and fusion of particles, producing dense coatings without the feedstock material being significantly heated. The bonding between the particles is associated with adiabatic shear instabilities caused by high strain deformation rate during impingement and occurs solely when the impact velocities of the particles range between certain critical values ("deposition window") [8]. Besides the ductile metallic materials, pure ceramic materials could be also successfully deposited as demonstrated by Yamada and co-workers [9].

Due to its ambient or low-temperature character (i.e. well below melting temperatures of the most of the sprayed materials), phase and composition changes of the original material feedstock are negligible (rendering post-spray heat treatments unnecessary) with virtually non-existent chemical decompositions or selective components evaporation. In-flight oxidation of the sprayed material, a process intensified at elevated temperatures, is suppressed and the absence of oxides improves the intrinsic bonding strength, resulting in the highest adhesion strengths among thermal spray processes [6]. Due to the lower porosity content and increased value of elastic moduli, the cold sprayed coatings are more susceptible to deformation induced cracking [10]. As primary and secondary thermal stresses are negligible in cold spray, peening stresses originating from the deformation upon particles impingement become dominant. Complex computational studies (e.g. Assadi et al. [11], Schmidt et al. [12]) were carried out in order to understand the stress build-up during cold spray.

Prior to coatings deposition, grit-blasting procedure is often employed in order to clean and degrease the substrate and to increase the layers adhesion by the means of coating-substrate mechanical interlocking. Furthermore, the procedure induces stresses of compressive nature into the surface layers of the substrate materials, which counteract the stress concentration invoked by the increased roughness and may increase the resistance of the substrates to fatigue crack initiation. 
The effect of the coatings thermal spray deposition on the fatigue properties of the bodies was studied in [13], [14], [15], [16]. It was demonstrated that the high-temperature deposition of the layers plays a crucial role in the fatigue properties of the specimens. For cold spray technology, a limited number of studies investigate the fatigue phenomenon (e.g. [17]). This study aims to describe the influence of cold spray $\mathrm{Ti}$ deposition on the fatigue properties of Ti6Al4V substrates. The results are compared with fatigue data of as-received and grit-blasted substrates and substrates with plasma deposited Ti layers. The specimens are further investigated using fractographic analysis and metallography, their element and phase composition is studied and their respective coatings moduli are estimated. Based on the obtained results, the factors leading to fatigue cracks formation are summarized.

\section{Experimental Setup}

\subsection{Specimens preparation}

Four sets of substrates, each consisting of six specimens were prepared: as-received (denoted "A"), grit-blasted ("GB"), grit-blasted with plasma deposited layers ("PS") and grit-blasted with cold sprayed layers ("CS"). The substrates were manufactured from Ti6Al4V Eli grade 5 material (DatumAlloys, Singapore). The composition of the material as determined by EDX method could be seen from Table 1 as well as the corresponding ASTM F-1580 standard requirements [18] for hard tissue replacement biograde materials. As could be seen from the table, the used Ti6Al4V alloy contained increased amount of aluminum as compared to the ASTM standard and with no other impurities detected in the material.

The $4 \mathrm{~mm}$ thick Ti6Al4V sheets were cut into symmetric substrates pre-designed for the needs of the fatigue experimental device (Fig. 1). The specimens were designed in order to localize the area of prospective crack initiation sites and facilitate more accurate crack detection. The symmetric design of the specimens allowed to carry out two measurements per one sample. Chemical degreasing was carried out in order to remove any oil or contaminant films from the substrate surfaces. For the grit-blasting procedure (employed for sets GB, PS, and CS), a blend of $\mathrm{SiC}$ and $\mathrm{Al}_{2} \mathrm{O}_{3}$ particles $(380-760 \mu \mathrm{m})$ was used.

Commercially available titanium powder (Titan Engineering, Singapore) was deposited onto the substrates using plasma and cold spray technologies. The powder morphology and cross-section investigation indicated sintered and crushed morphology of the particles with small debris partially attached to the bigger particles and inherent internal porosity below $0.1 \%$ threshold (Fig. 2). Laser analysis of the powder particle sizes (Fritsch Analysette A22 NanoTec) determined the particle sizes as 5-29 $\mu \mathrm{m}(5-95 \%$ weight quantile, Fig. 3). The composition of the Ti powder was verified using XRD (determined as $100 \%$ Ti, Fig. 4) and EDX techniques (Table 1). Selected important physical and mechanical properties of the Ti material relevant to the performed mechanical testing are provided in Table 2 along with the corresponding values of Ti6Al4V alloys.

For the deposition of the PS set, atmospheric plasma spray system (Praxair 4600 Module equipped with SG-100 plasma gun) with Ar/He gases was employed. The spray parameters were selected based on previous experimental work [19], [20] and could be seen from Table 3. Cold spray assembly used to produce the CS set (ITAM, Russian Academy of Science) was equipped with wear-resistant ceramics Laval nozzle and used purified He as the working and feeder gas. To aid in deposition of well-adhering and non-porous coatings, the helium gas temperature was increased to $533 \mathrm{~K}$ (Table 3), well below the temperature of $\alpha$-Ti $\rightarrow \beta$-Ti transition $(1155 \mathrm{~K})$ and the temperature indicated for initiation of the reaction with oxygen to form $\mathrm{TiO}_{2}(1470 \mathrm{~K})[1]$. Using the two technologies, the Ti powder was deposited onto both faces of the substrates with the target thickness of $700 \mu \mathrm{m}$. The thickness was selected to accentuate the effect of the layer on the properties of the coated samples while restraining a spontaneous delamination, spallation and cracking resulting from the residual stresses build-up. The actual thicknesses of the produced coatings could be seen from Table 4.

\subsection{Fatigue experiments}

The four specimen sets were subjected to fatigue testing using an electromagnetic computer controlled device SF-Test developed at CTU in Prague. One end of the flat specimens was clamped in the SF-Test anchorage (as cantilever-beam) while the free end was equipped with a ferromagnetic yoke and subjected to a symmetric cyclic bending load with a constant deflection of the free end (amplitude of $\pm 7 \mathrm{~mm}$, 
$\mathrm{R}=-1$ ). The loading frequency corresponded to the first natural resonance frequency of the mounted specimens (usually $70 \mathrm{~Hz}-110 \mathrm{~Hz}$ ) and was maintained using phase locked loop (PLL) technique. The critical area of the specimens was air-cooled during the testing.

The changes in the natural resonance frequency of the specimen-yoke system and, subsequently, the changes in the loading frequency are dependent on transient changes of the system dynamic behavior and the fatigue crack propagation [13]. The effect of the transient changes saturates in the beginning of the experiment and it is therefore possible to monitor the specimen cross-section damage from the measured frequency drop [21]. Based on the the previous research results [14], a frequency drop of $4 \mathrm{~Hz}$ was chosen as a fatigue test stopping condition. The fatigue life of the specimen was defined as the number of cycles at the stopping condition and corresponded to generally 30\%-60\% specimen cross-section damage. The obtained fatigue lives of the specimens are not affected by the significant variance in the damaged area due to the relatively high crack growth rate during the final stages of the experiments.

The Ti6Al4V substrates exhibited low internal damping and the PPL feedback of ST-Test device had to be adjusted. Several tested specimens were used for the adjustment and the measured fatigue lives of such specimens were not included in the results (marked * in Table 4).

\subsection{Specimen characterization}

The microstructure of the specimens was analyzed on polished samples and observed by light microscopy and Philips XL30 scanning electron microscope. Etching of the substrate material using Knoll reagent was used. The acquired SEM images of the deposits were used for the internal coatings porosity determination. The micro-morphology of the specimen free surfaces was assessed using SEM and their respective $R_{a}, R_{z}$ average roughness levels were measured according to ISO: 4287-1997 standard [22].

Fractographic analysis of the fatigued specimens was carried out using Jeol 5510LV SEM in "shadow" mode (a mixed signal from axial and off-axis BSE detectors) to reflect both the micro-morphology and the average atomic numbers of the specimen surfaces [14]. To analyze the fracture surfaces, static final rupture of the specimens using a standard tensile test device was carried out.

The chemical composition of the deposited layers was determined using XPert Pro X-ray diffractometer (Co $\mathrm{K}_{\alpha}, \mathrm{K}_{\beta}$ absorption filter) equipped with XCelerator detector (PANalytical B.V.) and EDAX XL-30 energy-dispersive X-ray spectroscope. Rietveld analysis of the acquired XRD spectra [23] was carried out in order to quantify the chemical composition.

\subsection{Coatings moduli calculations}

Using the measured resonance frequencies from the fatigue experiments, the coatings elastic moduli were obtained by method described in [13].

FEM modeling of bending vibration of uncoated, linear elastic isotropic substrate equipped with a yoke was carried out. Using several combinations of substrates moduli $(E)$ and densities $(\rho)$, it was found that the respective measured resonance frequencies of the bodies could be expressed as

$$
f_{\text {res }}=\frac{A}{\sqrt{\frac{\rho+B}{E}}}
$$

The constants A and B were determined by the FEM results and represent the yoke/sample geometry. In the case of coating-substrate composite, effective density of a substrate material was constructed

$$
\rho_{e f f}=\frac{m_{c}+m_{s}}{V_{s}}
$$

$\left(m_{c}, m_{s}\right.$ are the weights of the coating and the substrate, respectively and $V_{s}$ is the volume of the substrate), as well as an effective elastic modulus $E_{\text {eff }}$, which is a modulus of a non-coated substrate that would have the same bending stiffness as the substrate/coating composite. The effective modulus could be expressed from the momentum balance for specimen cross-section:

$$
M_{\text {applied }}=E_{s} w \int_{0}^{\frac{H}{2}} \frac{d \varepsilon}{d x} x^{2} d x+E_{c} w \int_{\frac{H}{2}}^{\frac{H}{2}+h} \frac{d \varepsilon}{d x} x^{2} d x=E_{\text {eff }} w \int_{0}^{\frac{H}{2}} \frac{d \varepsilon}{d x} x^{2} d x
$$


where $w$ is the width of the substrate, $x$ the distance from the cantilever clamp point, $E_{s}$ is the substrate modulus, $H$ is the thickness of the substrate $(4 \mathrm{~mm}), h$ is the measured coating thickness and $E_{c}$ is the calculated coatings modulus. Substituting the values of $\rho_{\text {eff }}(2)$ and $E_{\text {eff }}$ (derived from (3)) into (1), the modulus of the deposited coating could be calculated as

$$
E_{c}=\left[\frac{\rho_{\text {eff }}+B}{\left(\frac{A}{f_{\text {res }}}\right)^{2}}-E_{s}\right] \cdot \frac{\left(\frac{H}{2}\right)^{3}}{\left(\frac{H}{2}+h\right)^{3}-\left(\frac{H}{2}\right)^{3}}
$$

\section{Results and Discussion}

\subsection{Specimen characterization}

The surface micro-morphologies of the as-received substrates, grit-blasted substrates and plasma sprayed and cold sprayed coatings could be seen from Fig. 5. The grit-blasting procedure produced a roughened surface $\left(\mathrm{R}_{a} \sim 3 \mu \mathrm{m}\right)$ and introduced abrasive angular $\mathrm{Al}_{2} \mathrm{O}_{3}$ and SiC particles into the Ti6Al4V material. The presence of the embedded particles was also indicated by the increased concentration of $\mathrm{Al}$ and $\mathrm{Si}$ atoms detected on the substrate surface (Table 1). The surface of the cold sprayed deposit composed of protrusions formed by Ti particle agglomerates with sizes ranging from sub-micron to approximately $50 \mu \mathrm{m}$ (in accordance with the impact angle studies described by the groups of Binder [24] and C.-J. Li [25], Fig. 5) Due to the angular nature of the particles, the roughness of the cold sprayed surface increased to $11.3 \mu \mathrm{m}$ (Table 4). The surface of plasma sprayed deposits exhibited signs of splats splashing and a loss of the initial angular features of the material. The splashing resulted in a reduced roughness as compared to the cold sprayed counterparts (approximately $8.5 \mu \mathrm{m}$ ). Sub-micron particles of the condensates were observed in the coating surface.

The typical microstructures of the substrates could be seen from Fig. 6. The microstructure is typical for a cold-rolled Ti6Al4V sheet and contains $\alpha$-phase in a transformed $\beta$-phase matrix. The grit-blasting procedure (sets GB, CS, PS) caused a formation of a plastically deformed area in the uppermost layers of the substrates (Fig. 6), in accordance with [4]. Due to the relatively low modulus and high yield strength of Ti6Al4V alloy, the thickness of the layer did not exceed $\leq 10 \mu \mathrm{m}$. The petal-like splashing and melting of the substrate material observed by Li et al. [26] was not experimentally confirmed in the plasma deposits.

The microstructure of the investigated coatings is presented in Fig. 7. The plasma sprayed coatings exhibited a semi-sintered structure consisting of clusters of splats of various degree of flattening, unmelted particles, intra-splat cracks and inter-splat pores. Three distinct chemical compositions of the material were observed in the plasma deposit: $\mathrm{TiN}\left(96.9 \mathrm{wt} \% \mathrm{Ti}, 3.1 \mathrm{wt} \% \mathrm{~N}\right.$, bright splats in $\mathrm{Fig} .7$ ), $\mathrm{Ti}_{3} \mathrm{O}$ (61.3 wt\% Ti, $38.7 \mathrm{wt} \% \mathrm{O}$, dark splats) and a mixture of the two compounds (results of area analysis of the coatings could be seen from Table 1). The Rietveld analysis of the XRD spectra indicated the composition of the coatings as $71.6 \% \mathrm{TiN}, 28.4 \% \mathrm{Ti}_{3} \mathrm{O}$, i.e. no initial $\mathrm{Ti}$ phase was retained during the plasma process (Fig. 4). The full transformation of $\mathrm{Ti}$ into $\mathrm{TiN}$ (fcc) and $\mathrm{Ti}_{3} \mathrm{O}$ (hcp) phases is in accordance with other studies [27], [28] and is a result of the inherent high-temperature nature of the plasma process. The porosity of the plasma deposited coatings was determined as 10.2\% (Table 5). Elongated, non-uniformly distributed cracks were detected at the substrate-coating interface, possibly a consequence of residual stresses alleviation during the cooling phase.

The cold sprayed coatings exhibit a dense structure with no apparent splat boundaries. No morphological features associated with the successive nozzle passes were observed and the interfaces between substrates and coatings were indiscernible along their entire span. The total coating porosity reached $0.5 \%$ and was of non-connected, individual pores nature (Table 5). The composition of the powder feedstock was retained (100\% $\alpha$-Ti, Fig. 4) and no additional phases were detected.

\subsection{Fatigue experiments and coatings moduli calculations}

The obtained results of the fatigue test experiments could be seen from Table 4 and Weibull probability plot in Fig. 8, representing the cumulative probability of failure of the components for a given number of cycles. The influence of each surface treatment technology was characterized by the relative fatigue life 
$R_{f}=\frac{N_{s}}{N_{a}}$, defined as the ratio of average fatigue life of the respective set to the average fatigue life of the as-received set.

The average fatigue life of the as-received Ti6Al4V set was 462949 cycles (approximately $72 \%$ higher as compared to identical-geometry steel substrates [14], probably due to superior yield strength and tensile strength of the Ti6Al4V alloy).

The implementation of the grit-blasting procedure significantly increased the fatigue lives of the tested specimens $\left(R_{f}=1.81,838966\right.$ cycles). The increase could be associated to the suppression of the crack initiation by introduction of compressive peening stresses into the specimen surfaces through the bombardment. This result is in direct contrast with the previous study [13], where the grit-blasting procedure did not result in any demonstrable alteration in the measured fatigue lives of low carbon steel specimens. The possible explanation of this difference could be in different responses to the induction of the stresses of the two materials.

The plasma sprayed specimens exhibited a substantial deterioration of the fatigue properties with relative lives comparable to that of the as-received set $\left(R_{f}=1.16,618729\right.$ cycles). Such decrease is in direct contrast with the previous study [13] where the fatigue lives of the grit-blasted low-carbon steel bodies exhibited a substantial increase upon plasma deposition of ceramic materials. As the average thermal expansion coefficient of the deposited layer is assumedly higher $\left(71.6 \% \mathrm{TiN}, \alpha_{T}=9.35 \times 10^{-6} \mathrm{~K}^{-1}\right.$, no literature on $\alpha_{T}$ of $\left.\mathrm{Ti}_{3} \mathrm{O}, 29.4 \%\right)$ than that of the substrate $\left(\alpha_{T}=8.6 \times 10^{-6} \mathrm{~K}^{-1}\right.$, Table 2), the secondary stresses in the substrate should be of compressive nature in the substrates, improving the total stress condition during testing.

The possible explanation of the observed deterioration of the fatigue properties after plasma spraying could consist in the phenomena suggested by Kroupa [10]: under compression, an elastic closing of micro-cracks in the coatings leads to a gradual decrease of the micro-crack density and to an increase of the coatings modulus in compression. Under tensile stresses, the voids and cracks grow by inelastic processes and their respective density therefore gradually increases, resulting in a decrease of the modulus in tension. According to the measurements by Musalek et al. [29], the difference of the two moduli could amount to $10 \times$ in the case of ceramic coatings. During the bending, the stresses in the coatings on the compressed side need to be compensated by tensile stresses in the other coating side. However, due to the difference in the moduli in tension and compression, some of the tensile stresses will be transferred into the substrate, causing an increase in the total stresses upon superposition with the bending stresses.

Similarly to plasma sprayed samples, adverse effect of cold spray deposition of Ti layers on the fatigue lives of the previously grit-blasted specimens was detected $\left(R_{f}=0.91,421772\right.$ cycles). As the cold sprayed coatings contain negligible amount of porosity $(0.5 \%$, Table 5$)$, the cracking in the substrate could be caused by a mechanism different from the plasma sprayed coatings. The following explanations are provided for discussion of the obtained results:

The well-sintered structure of the cold sprayed coatings represents a compact layer of added welladherent material and due to its further distance from the neutral plane experiences increased stress levels during the cyclic bending as compared to the standalone non-coated substrate of $4 \mathrm{~mm}$ thickness. Upon cycling, the vertical failure of the coatings [30] by a propagation of a crack could be transferred to the underlying substrate, resulting in the measured inferior fatigue lives. This explanation is further supported by the observed crack initiation on the front substrate surfaces below the coatings (Fig. 9).

Further to that, the quenching stresses are not likely to arise as the temperature of the particles stayed well below the material melting temperature in cold spraying. Also, the secondary stresses effect should not be pronounced as the thermal expansion coefficients of Ti coating and Ti6Al4V materials are almost equal. However, the added Ti material is in compression due to the effect of the discussed peening stresses. The compressive stresses in the coatings could be balanced by an induction of tensile stresses in the previously grit-blasted substrates. Such increase in the internal stresses could lead to an earlier crack initiation and cause the apparent deterioration in the fatigue properties of the cold spray coated specimens.

The discussed interpretations of the deterioration of the fatigue properties of the plasma spray and cold spray deposited specimens are supported by a phenomena discovered during the course of the experimental work: during the initial stages of cycling (i.e. less than 5000 cycles), a spontaneous coating delamination occurred for several specimens. It was found that the relative fatigue lives of such specimens markedly increased ( $835387, R_{f}=1.80$ ) and it could therefore be concluded that the negative effect of cold and 
plasma spray layers deposition is of temporary nature.

The measured resonance frequencies of the specimens allowed determination of the elastic moduli of the deposited coatings. The calculated values of $7.2 \mathrm{GPa}$ (plasma sprayed) and $31.2 \mathrm{GPa}$ (cold sprayed) (Table 5) represent approximately $6.2 \%$ and $31.6 \%$ of the modulus of bulk titanium (116 GPa), respectively. The relatively small value of the plasma deposited coatings modulus is presumably a consequence of elastic openings and partial closings of the porosity and micro-cracks present in the coatings [10], while the higher value of the modulus of cold spray deposited coatings is presumably caused by the substantially decreased porosity content.

\subsection{Fractographic analysis}

It was found that the fatigue cracks in the substrates grew by striation mechanisms and the micromorphology of the fracture surfaces could be distinguished from the final static rupture. Their respective initiation sites and propagation directions could be seen from Fig. 9.

The crack initiation sites in the as-received set were located at the side surfaces near the specimen edges. The cracks generally had an $1 / 4$ elliptical shape with crack openings on both front and side surfaces of the specimen.

In the case of the grit-blasted and plasma sprayed samples, the cracks initiated on the side $(4 \mathrm{~mm})$ surfaces at a distance from the edges (possibly due to a favorable fracture-mechanics situation arisen from the internal stresses condition) and had an $1 / 4$ elliptical shape.

The substrate crack faces exhibited features corresponding to contact wear up to the depths of $150 \mu \mathrm{m}$ from the substrate surfaces (Fig. 10). Small particles containing Al and Si oxides (probably crushed gritblasting particles) were found in the area. The different fracture micro-morphology in the area could be explained by the effect described in [31]: upon rupture of the layer, an extrusion of the material in the direction perpendicular to the fracture surfaces causes an increased contact pressures during the successive opening and closing of the crack.

Unlike their plasma sprayed counterparts, the fatigue cracks in the cold sprayed substrates originated below the coatings from the front faces (i.e. the surfaces below the deposited coatings). The fatigue cracks had an $1 / 2$ elliptical shape with crack openings at the front surfaces of the specimen. The observations correspond to the provided explanation on the deterioration of the fatigue properties of cold sprayed set via transferring of the coatings cracks into the substrate.

The obtained results on the crack initiations in the substrates below both types of coatings (i.e. from the $4 \mathrm{~mm}$ side surfaces for grit-blasted and plasma sprayed samples and from below the coatings for cold sprayed specimens) correspond to the study by Kovarik et al. [13]. In this study, the cracks in the substrates with coatings extending the fatigue lives originated from the non-coated sides while the cracks in the substrates with coatings deteriorating the fatigue properties originated from the front surfaces below the coated layers.

The fatigue fracture surfaces in the coatings form a natural extension of their substrate counterparts and their morphology is similar to their respective final static rupture surfaces. The periodic contact of the two fracture surfaces lead to an obliteration of the initial structure of the coatings. The extent of such obliteration depends on the lengths of the corresponding cracks (i.e. the number of opening-closing cycles): the surfaces are more obliterated in the vicinity of the crack initiation site (more cycles) than the the surfaces at longer distances from their initiations (Fig. 11). In the plasma sprayed coatings, spallation of the splats caused intensified obliteration of the crack surfaces as the fragmented particles acted as abrasive agents. Due to the obliteration, the crack initiation sites and propagation directions could not be safely determined in the coatings.

\section{Conclusions}

Four sets of Ti6Al4V-alloy specimens (as-received, grit-blasted, cold sprayed and plasma sprayed) were subjected to cyclic-bend testing to ascertain the influences of the surface treatments on their fatigue resistance. Microstructure of typical samples from each set was investigated as well as porosity, chemical composition, and moduli of the plasma and cold spray deposited coatings. From the obtained results it could concluded that: 
- the grit-blasting procedure substantially increases the fatigue crack resistance of the substrates ( $+81 \%$ as compared to the as-received set), probably due to induction of peening stresses into the upper layers of the material;

- the cold spray deposition of the Ti powder onto the Ti6AlV4 substrate produced dense (porosity $0.5 \%$ ) coatings with surface roughness of $11.3 \mu \mathrm{m}$, while retaining the the phase composition of the feedstock material $(100 \% \mathrm{Ti})$; the compact layers exhibit elastic moduli values of $36.7 \mathrm{GPa}$, approximately $32 \%$ of bulk Ti;

- the plasma spray deposition leads to porous coatings $(10.2 \%)$ of the surface roughness of $8.5 \mu \mathrm{m}$, with the feedstock material completely transformed to nitrides and oxides (71.6wt\% TiN, $28.4 \mathrm{wt} \%$ $\mathrm{Ti}_{3} \mathrm{O}$ ); the elastic modulus of the plasma sprayed coatings reached 7.2 GPa;

- both plasma spray and cold spray deposition of Ti feedstock onto grit-blasted surfaces decreased the measured fatigue lives; the deterioration is of temporary nature and by removal of the layers, the specimens fatigue lives returned to the values comparable with grit-blasted set;

- the decreased fatigue life of the plasma sprayed set could be attributed to an asymmetric substrate loading during the bending, resulting from a significant difference in the deposited coatings moduli in compression and tension;

- cold spray deposition of Ti layers let to a deterioration of the fatigue lives to the lowest values among the tested sets (91\% of the as-received set); the decrease could be attributed to a vertical cracking of the coatings followed by the cracks transfer into the substrates, and compensation of the residual peening stresses in the coatings by induction of tensile stresses in the substrates;

- fractographic analysis of the deposits enabled differentiating the areas of the fracture surfaces that underwent the cyclic opening/closing from the areas of the final rupture; the areas were characteristic by signs of contact wear of the fracture surfaces, causing obliteration of the initial structure; due to the obliteration, the crack initiation sites and propagation directions could not be accurately identified in the coatings;

- different modes of the fatigue crack initiation and propagation were identified in the substrate material; it was shown that the crack initiation sites and propagation direction correspond to the effect of the surface treatment on the respective average fatigue life of the given set: for the sets with relative fatigue lives above 1.0 (grit-blasted, plasma sprayed), the cracks initiated from the side surfaces of the substrates while for cold sprayed specimens (relative fatigue life below 1.0), the initiation sites were below the coatings at the substrates front faces.

\section{Acknowledgments}

The authors would like to express their gratitude to the following colleagues who have helped during this project: Mr. Kelvin Loke from Singapore Technologies Kinetics Ltd., Singapore for his help in preparation of the cold sprayed specimens, and from Institute of Materials Science and Engineering, Faculty of Mechanical Engineering, Brno University of Technology Mrs. Drahomira Janova for the microstructure and EDX investigations and Ms. Pavla Roupcova for X-ray diffractometry and Rietveld analyses of the used materials.

The Project has been funded from the SoMoPro programme. Research leading to these results has received a financial contribution from the European Community within the Seventh Framework Programme (FP/2007-2013) under Grant Agreement No. 229603. The research is also co-financed by the South Moravian Region.

The research performed at CTU was supported by the Czech Science Foundation project GACR $\mathrm{P} 108 / 12 / 1872$.

[1] D.M. Brunette, P. Tengvall, M. Textor, P. Thomsen, Titanium in Medicine, Springer, 2001

[2] S.J. Ding, C.P. Ju, J.H.C. Lin, J Biomed Mater Res, 44 (3), 1999, 266-279 
[3] J. Cizek, K.A. Khor, Surf Coat Technol, 206 (8-9), 2012, 2181-2191

[4] P. Fauchais, J Phys. D, 37 (9), 2004, R86-R108

[5] J. Matejicek, S. Sampath, P.C. Brand, H.J. Prask, Acta Mater, 47 (2), 1999, 607-617

[6] A. Papyrin, V. Kosarev, S. Klinkov, A. Alkimov, V. Fomin, Cold Spray Technology, Elsevier, 2007

[7] R.S. Lima, A. Kucuk, C.C. Berndt, J. Karthikeyan, C.M. Kay, J. Lindemann, J Mater Sci Lett, 21 (21), 2002, 1687-1689

[8] T. Klassen, F. Gärtner, T. Schmidt, J.O. Kliemann, K. Onizawa, K.R. Donner, H. Gutzmann, K. Binder, H. Kreye, Mat.-wiss. u. Werkstofftech., 41 (7), 2010, 575-584

[9] M. Yamada, M.E. Dickinson, K. Shima, N.T. Salim, H. Nakano, M. Fukumoto, Proc. International Thermal Spray Conference, 2011, 330-335

[10] F. Kroupa, J Therm Spray Technol, 16 (1), 2007, 84-95

[11] H. Assadi, F. Gärtner, T. Stoltenhoff, H. Kreye, Acta Mater, 51 (15), 2003, 4379-4394

[12] T. Schmidt, H. Assadi, F. Gärtner, H. Richter, T. Stoltenhoff, H. Kreye, T. Klassen, T, J Therm Spray Technol, 18 (5-6), 2009, 794-808

[13] O. Kovarik, J. Siegl, Z. Prochazka, J Therm Spray Technol, 17 (4), 2008, 525-532

[14] J. Siegl, J. Bensch, J. Cizek, K.A. Khor, Acta Technica CSAV, 52 (3), 2007, 205-215

[15] R. Musalek, O. Kovarik, T. Skiba, P. Hausild, M. Karlik, J. Colmenares-Angulo, Intermetallics, 18 (7), 2010, 1415-1418

[16] R.C. Souza, M.P. Nascimento, H.J.C. Voorwald, W.L. Pigatin, Corros Rev, 21 (1), 2003, 75-96

[17] K. Binder, F. Gärtner, T. Klassen, Proc. International Thermal Spray Conference, 2011, 2011, 879884

[18] ASTM Standard F-1580, Standard Specification for Titanium and Titanium-6 Aluminum-4 Vanadium Alloy Powders for Coatings of Surgical Implants, ASTM International, 2007

[19] J. Cizek, Thermally Sprayed Bio-Ceramic Coatings: a Study on Process Parameters Influence on Coating Properties, Nanyang Technological University, 2010

[20] J. Cizek, K.A. Khor, Z. Prochazka, Mat Sci Eng C, 27 (2), 2007, 340-344

[21] J. Siegl, P. Kantor, J. Adamek, Proc. 14th Int. Conference on Surface Modification Technologies, ASM International, 2001, 64-70

[22] ISO standard 4287, Geometrical Product Specifications (GPS) - Surface texture: Profile method Terms, definitions and surface texture parameters, International Organization for Standardization, 1997

[23] H.M. Rietveld, Acta Cryst, 22, 1967, 151-152

[24] K. Binder, J. Gottschalk, M. Kollenda, F. Gärtner, T. Klassen, J Therm Spray Technol, 20 (1-2), 2011, 234-242

[25] C.J. Li, W.Y. Li, Y.Y. Wang, H. Fukanuma, Proc. International Thermal Spray Conference 2003: Advancing the Science and Applying the Technology, 2003, 91-96

[26] L. Li, X.Y. Wang, G. Wei, A. Vaidya, H. Zhang, S. Sampath, Thin Solid Films, 468 (1-2), 2004, $113-119$

[27] L. Xiao, D. Yan, J. He, L. Zhu, Y. Dong, J. Zhang, X. Li, Appl Surf Sci, 253 (18), 2007, 7535-7539 
[28] A. Kobayashi, Surf Coat Technol, 132 (2-3), 2000, 152-157

[29] R. Musalek, J. Matejicek, M. Vilemova, O. Kovarik, J Therm Spray Technol, 19 (1-2), 2010, 422-428

[30] L. Xie, D. Chen, E.H. Jordan, A. Ozturk, F. Wu, X. Ma, B.M. Cetegen, M. Gell, Surf Coat Technol, $201(3-4), 2006,1058-1064$

[31] M.B. Prime, T. Gnäupel-Herold, J.A. Baumann, R.J. Lederich, D.M. Bowden, R.J. Sebring, Acta Mater, 54 (15), 2006, 4013-4021 


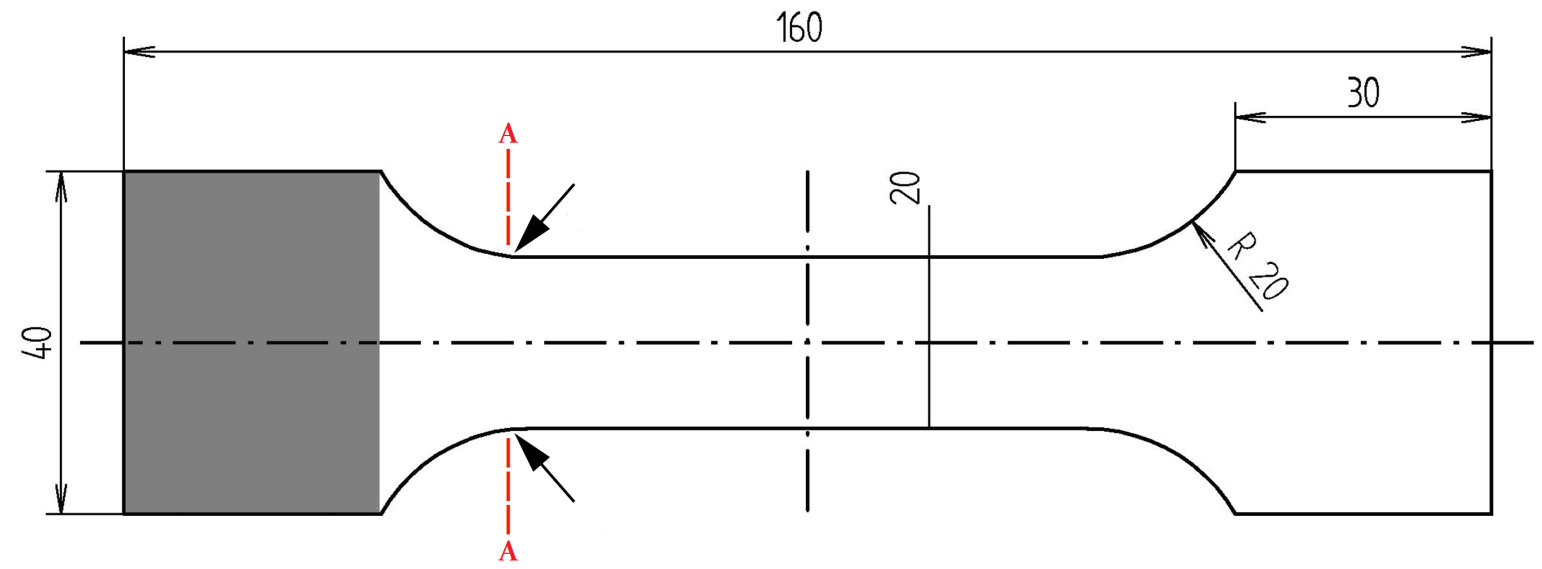

Figure 1: Geometry of standard fatigue test specimens (dimensions in mm; thickness $4 \mathrm{~mm}$ ). Arrows indicate crack initiation sites, gray area represents cantilever clamping area (after [14])
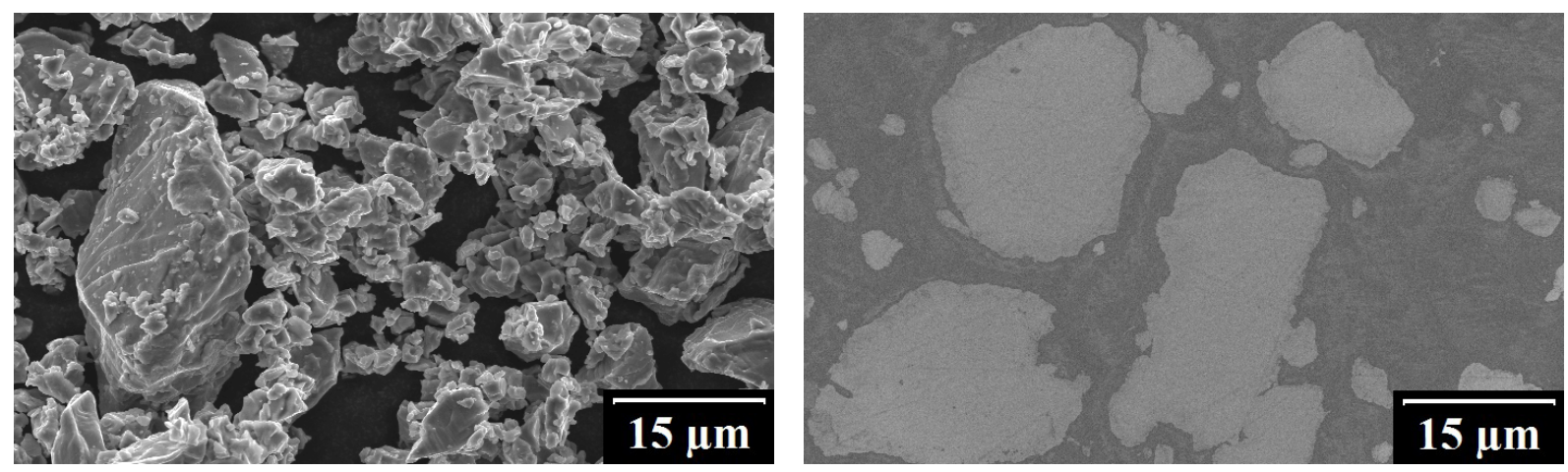

Figure 2: Titanium powder morphology and cross-section features 


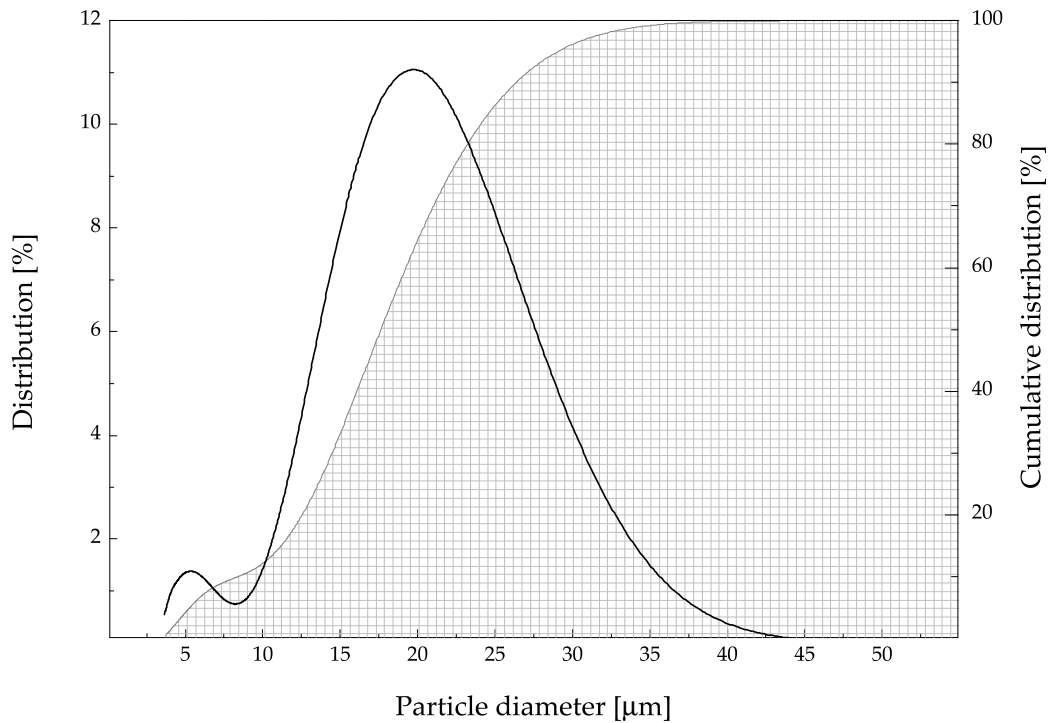

Figure 3: Measured Ti powder particle size distribution 


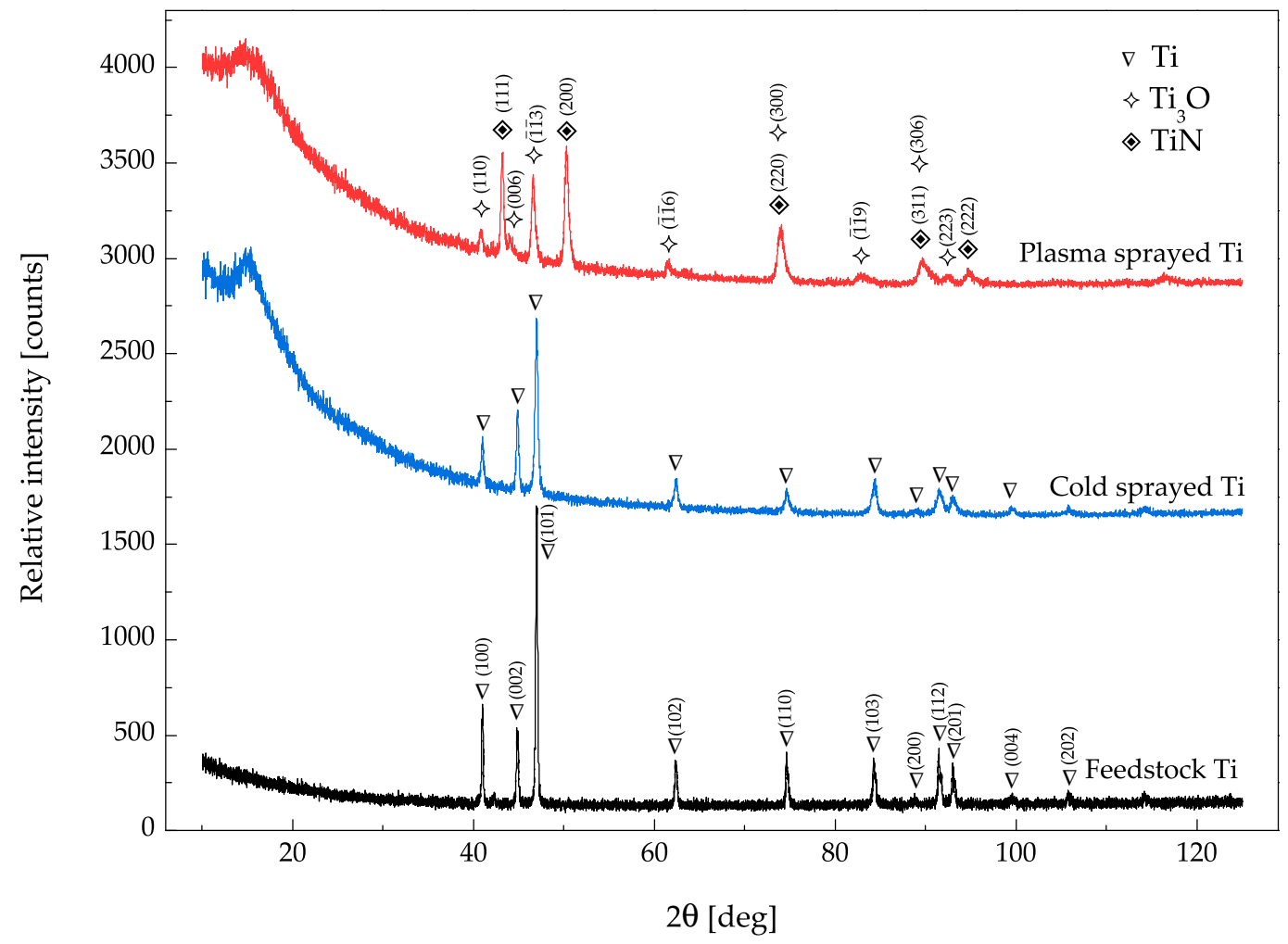

Figure 4: XRD patterns of Ti powder feedstock and deposited cold sprayed and plasma sprayed coatings 


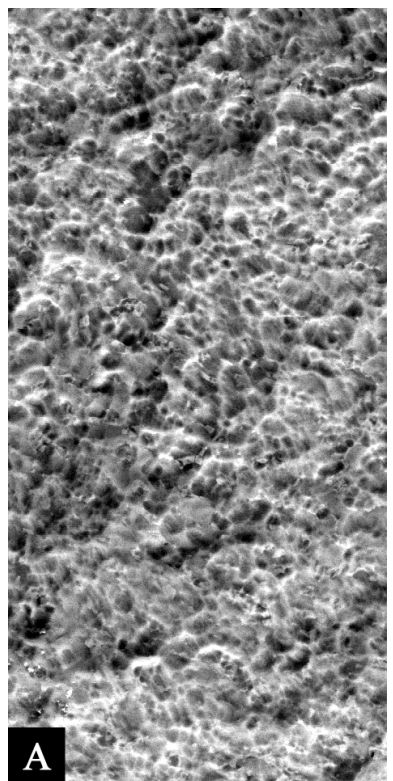

(a) $\mathrm{A}$

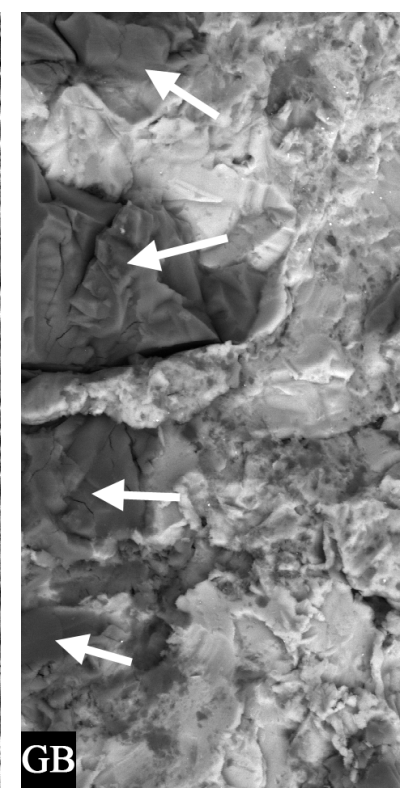

(b) GB

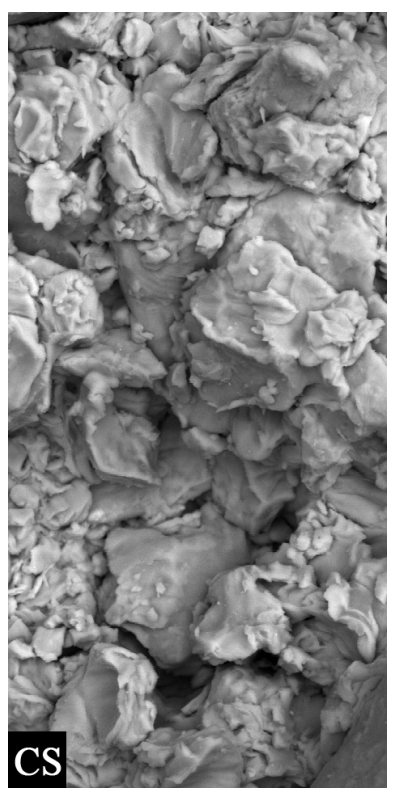

(c) CS

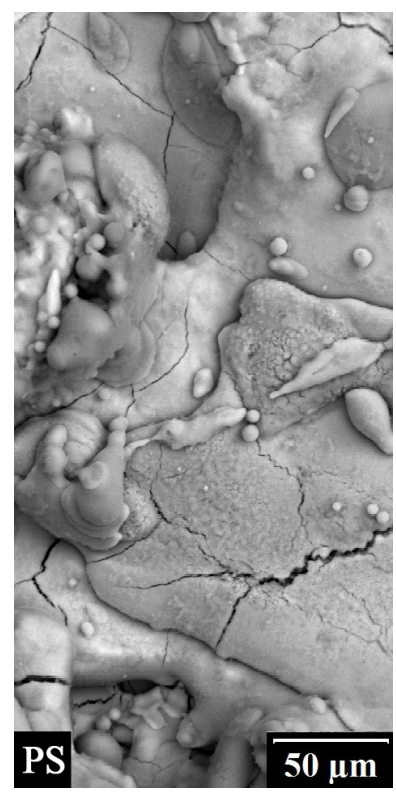

(d) PS

Figure 5: Surface morphology of the a) as-received b) grit-blasted c) cold sprayed d) plasma sprayed specimens; arrows indicate embedded $\mathrm{Al}_{2} \mathrm{O}_{3}$ and $\mathrm{SiC}$ grit-blasting particles

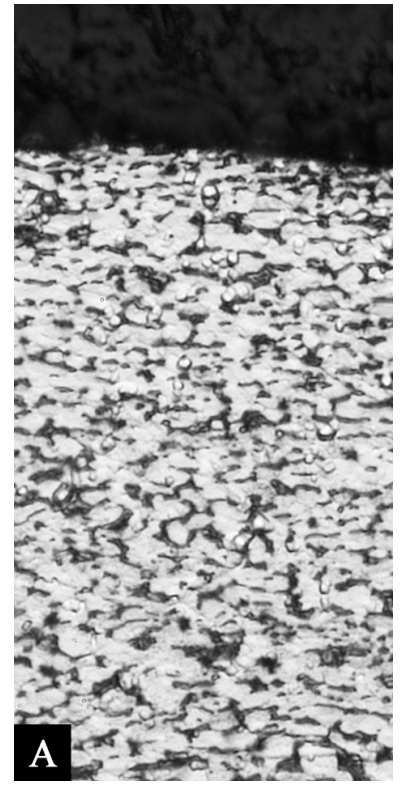

(a) $\mathrm{A}$

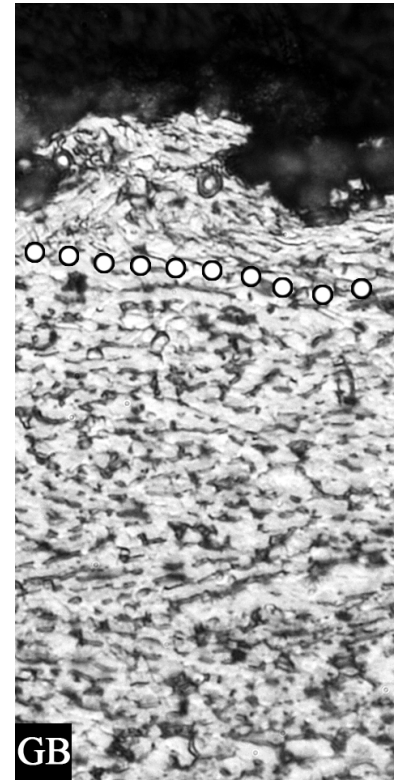

(b) GB

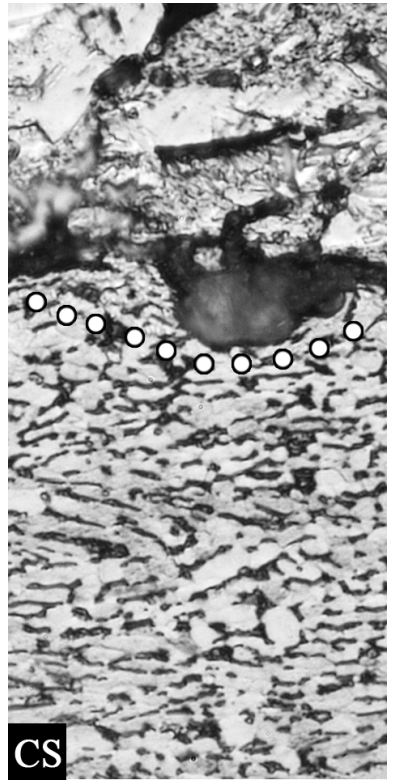

(c) $\mathrm{CS}$

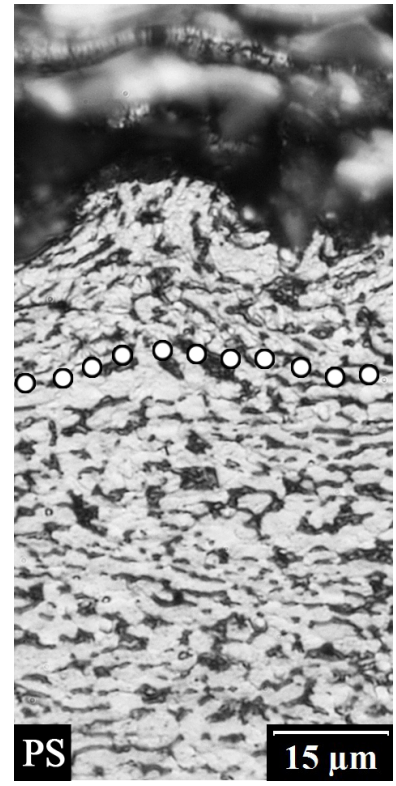

(d) PS

Figure 6: Microstructure of a) as-received b) grit-blasted c) cold-sprayed d) plasma sprayed substrates below the surface (light microscope, Knoll reagent); dots indicate surface areas influenced by grit-blasting procedure 

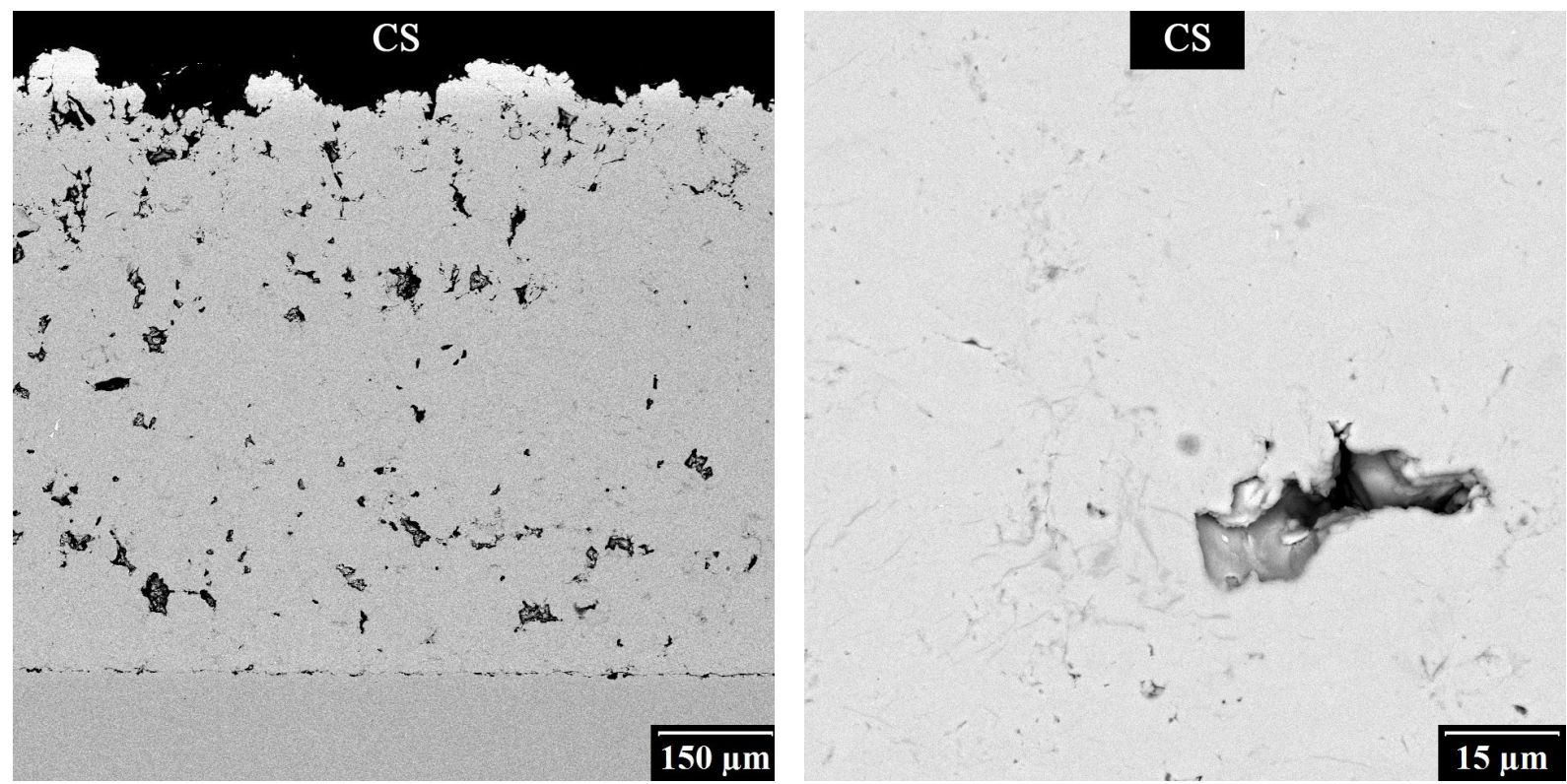

(a) CS

(b) CS
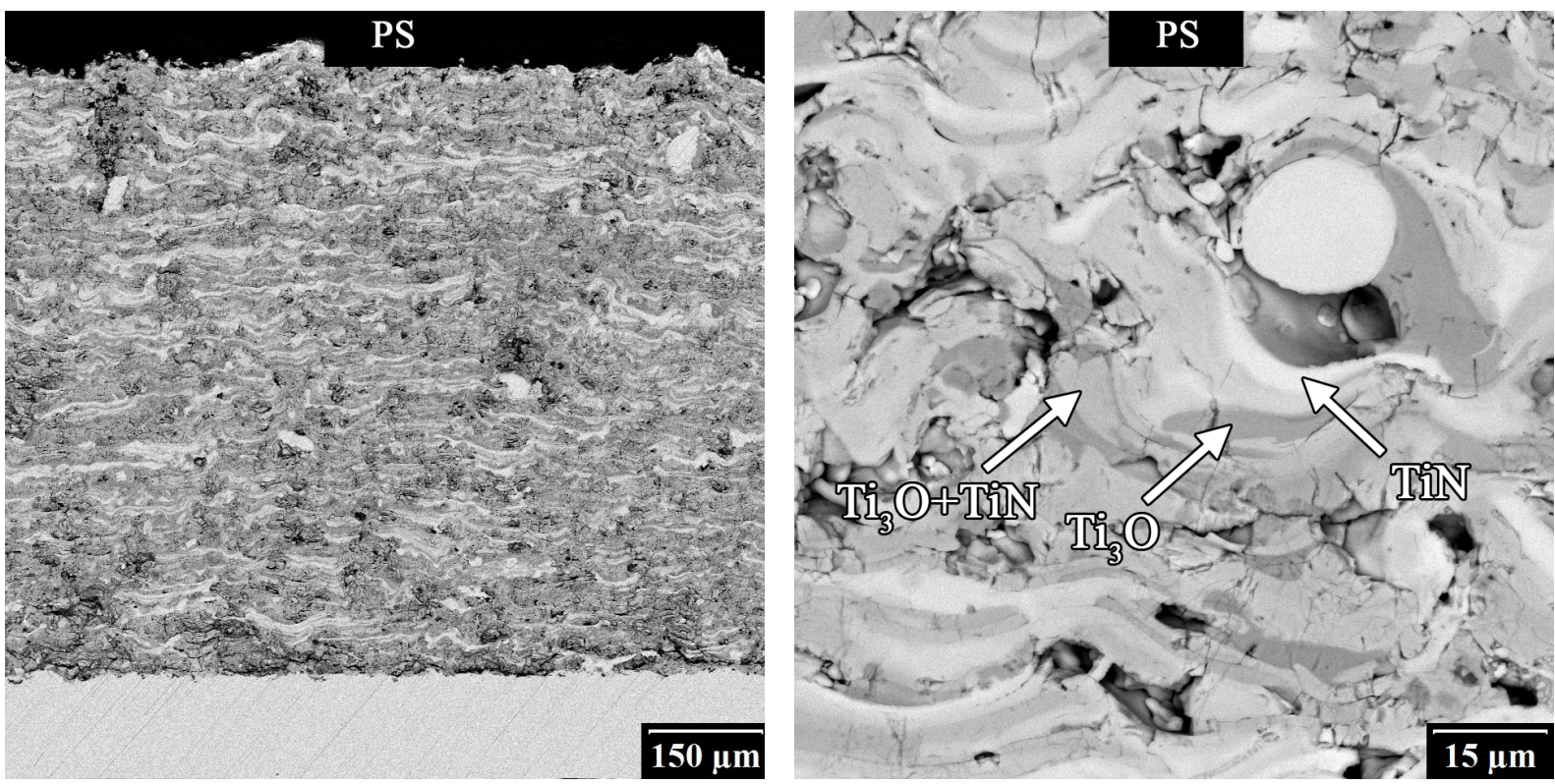

(c) PS

(d) PS

Figure 7: Microstructure of a-b) cold sprayed c-d) plasma sprayed coatings (SEM, shadow mode) 


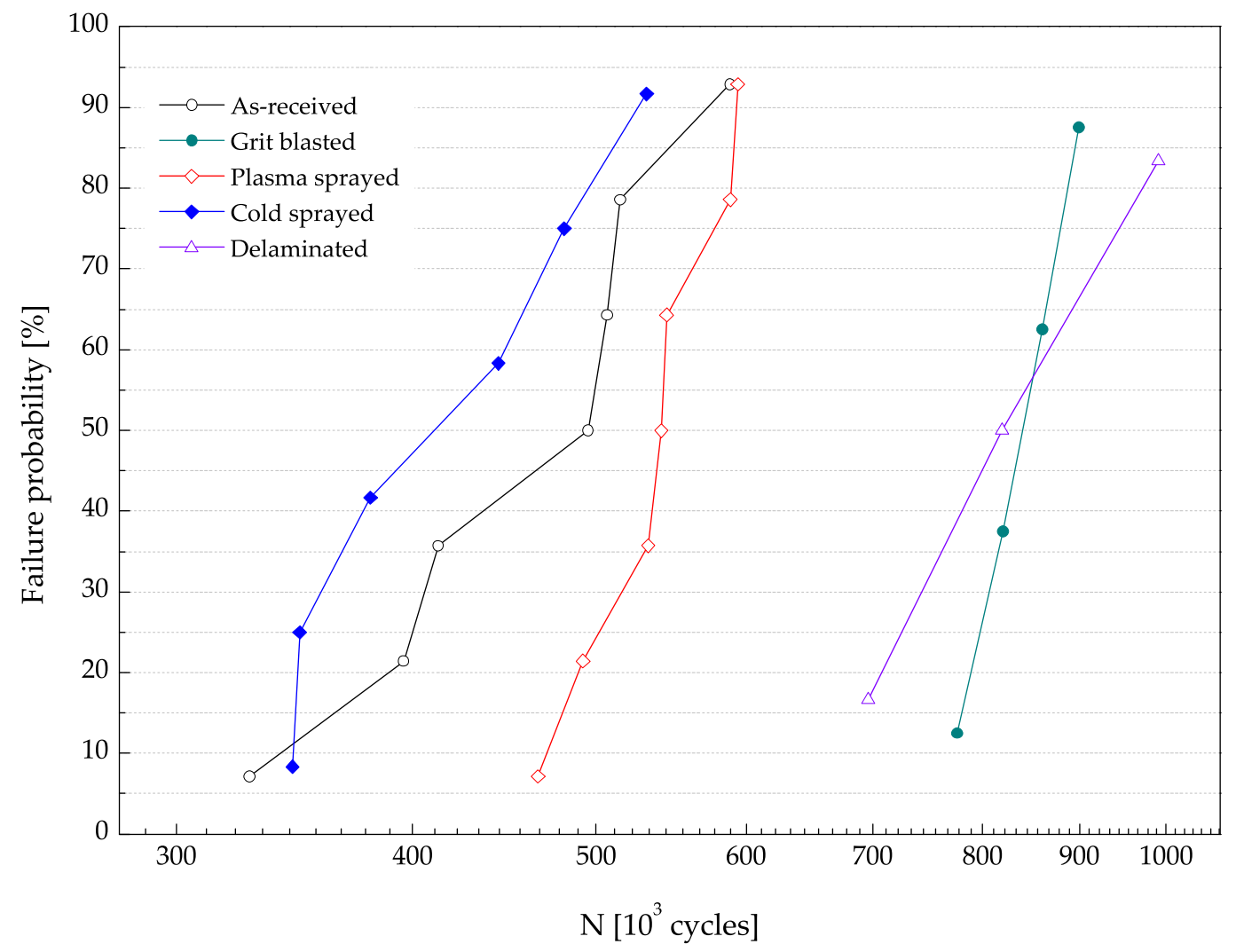

Figure 8: Weibull plot of fatigue test results 

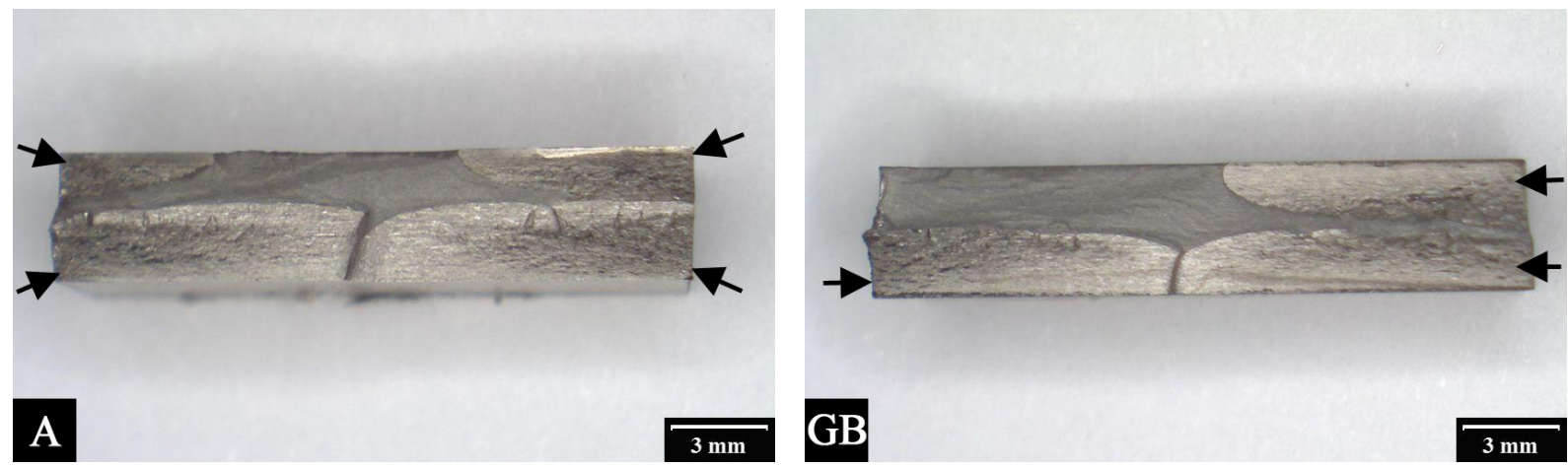

(a) $\mathrm{A}$

GB

$3 \mathbf{~ m m}$

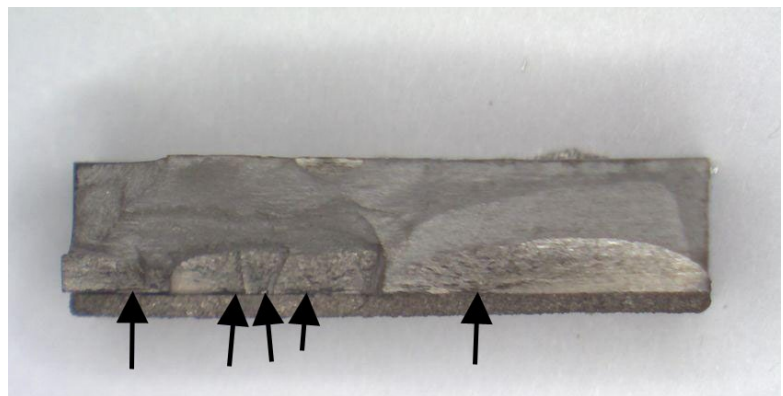

CS

$3 \mathrm{~mm}$

(b) GB

(c) $\mathrm{CS}$

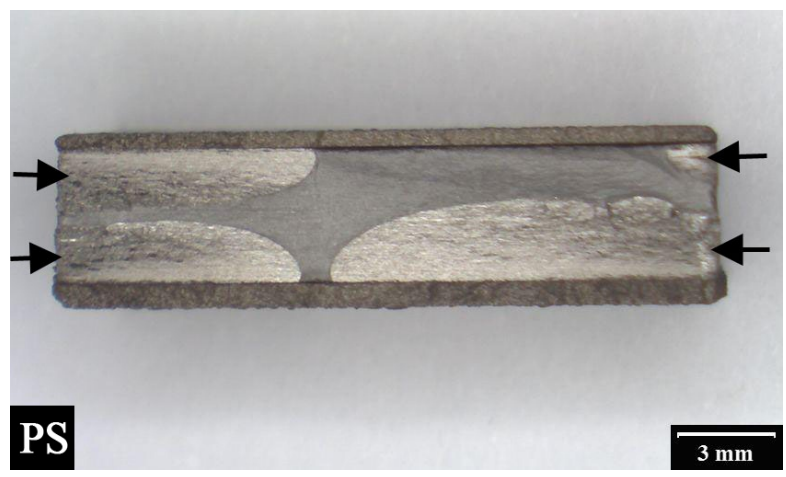

(d) PS

Figure 9: Typical fatigue crack shapes, initiation sites and propagation directions of different specimen sets

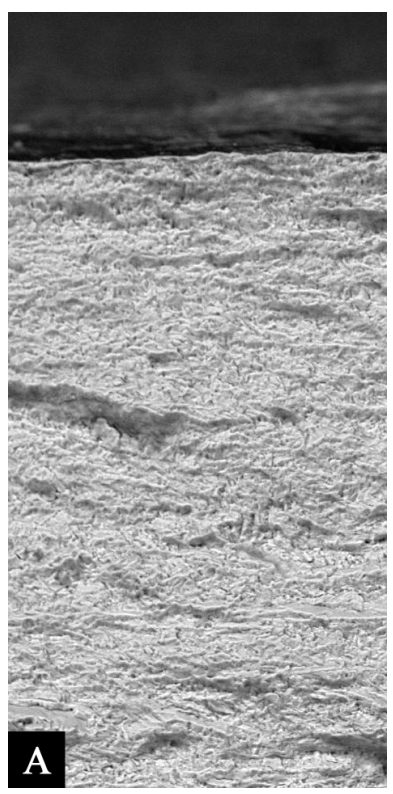

(a) $\mathrm{A}$

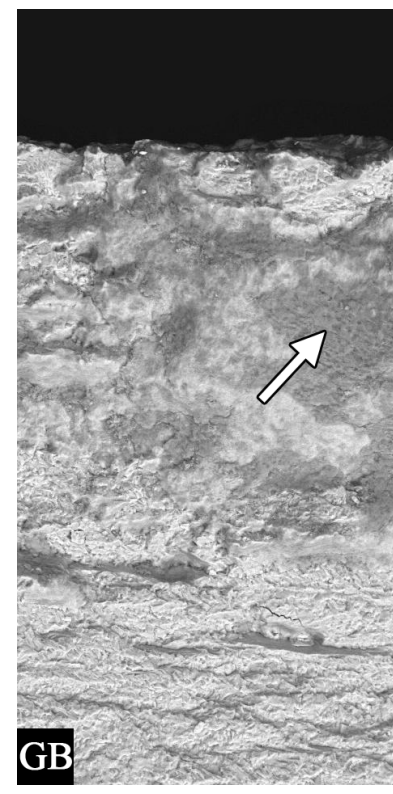

(b) GB

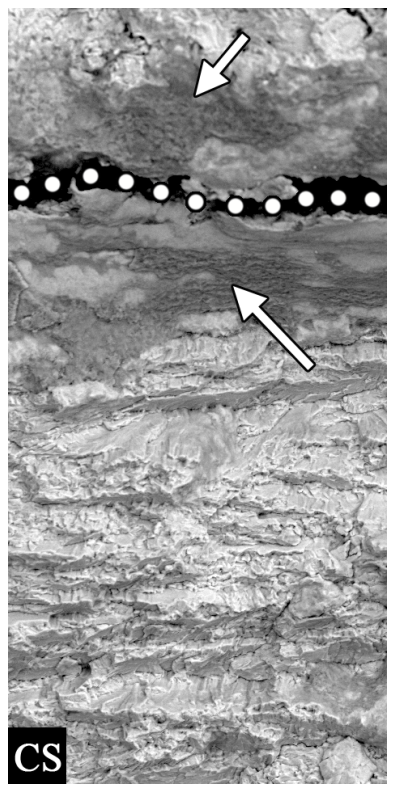

(c) $\mathrm{CS}$

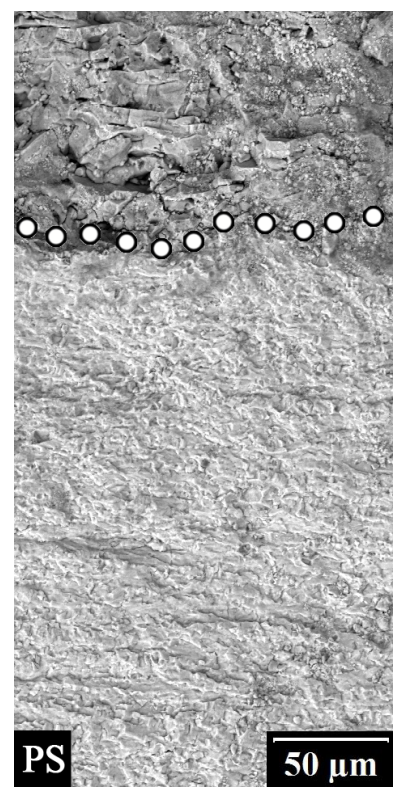

(d) PS

Figure 10: Fatigue crack surface morphologies in substrates. The fracture morphology of grit-blasted and cold sprayed substrates was obliterated by crushed abrasive particles near the substrate surface (contact wear-like, indicated by arrows) 


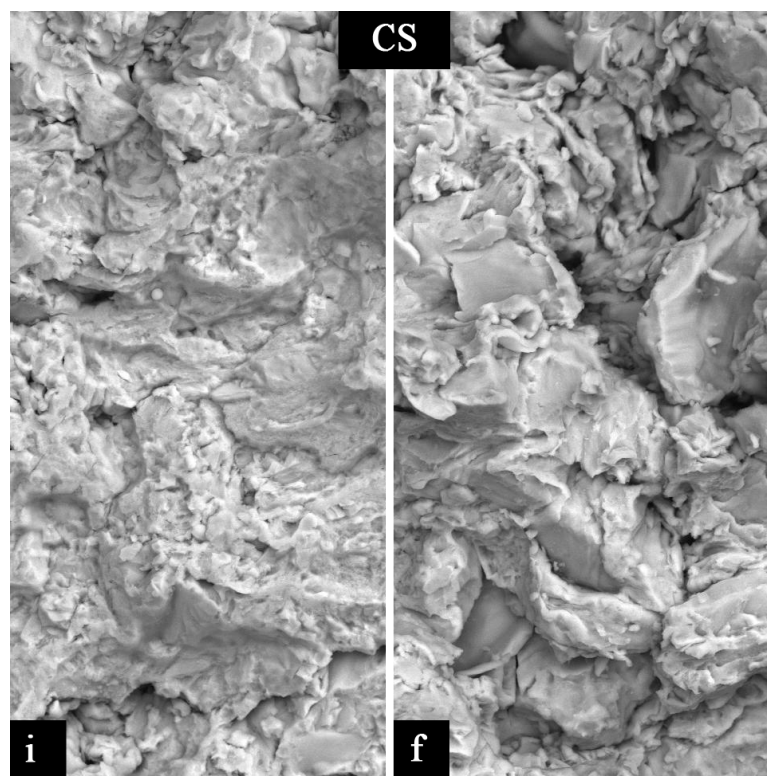

(a) CS

(b) GB

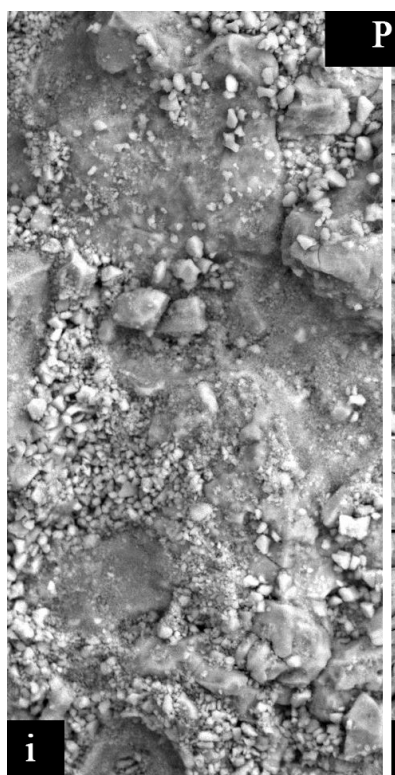

(c) CS

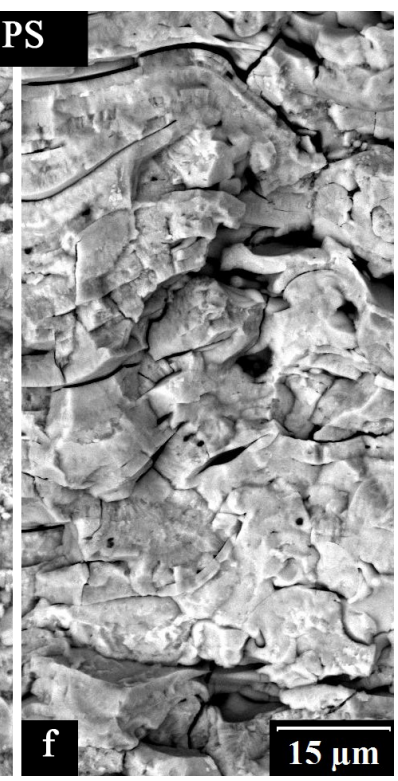

(d) PS

Figure 11: Fatigue crack surface morphologies in a,b) cold spray c,d) plasma sprayed coatings at various distances from the initiation site: a,c) at initiation site [higher number of cycles], b,d) at crack front [lower number of cycles]

Table 1: Element composition of respective materials used

\begin{tabular}{|c|c|c|c|c|c|c|c|}
\hline \multirow[t]{3}{*}{ Element } & \multicolumn{7}{|c|}{ Content $[\mathrm{wt} \%]$} \\
\hline & \multicolumn{2}{|c|}{ Powder } & \multicolumn{3}{|c|}{ Substrate } & \multicolumn{2}{|c|}{ Coatings } \\
\hline & ASTM* & feedstock & $\mathrm{ASTM}^{*}$ & non-treated & grit-blasted & $\mathrm{PS}$ & $\mathrm{CS}$ \\
\hline $\mathrm{Ti}$ & bal. & 95.0 & bal. & 89.0 & 73.1 & 79.0 & 96.4 \\
\hline $\mathrm{Al}$ & & & $5.50-6.75$ & 7.4 & 12.0 & & \\
\hline $\mathrm{V}$ & & & $3.50-4.50$ & 3.6 & 3.9 & & \\
\hline $\mathrm{O}$ & 0.40 & 3.3 & 0.20 & & 8.0 & 18.0 & 0.8 \\
\hline $\mathrm{Si}$ & & & & & 3.8 & & \\
\hline $\mathrm{Fe}$ & 0.50 & & 0.30 & & & & \\
\hline $\mathrm{C}$ & 0.08 & & 0.08 & & & & \\
\hline $\mathrm{H}$ & 0.05 & & 0.015 & & & & \\
\hline $\mathrm{N}$ & 0.05 & 1.8 & 0.05 & & & 2.9 & 2.8 \\
\hline
\end{tabular}

*Chemical requirements for bio-grade Ti powder and Ti6Al4V substrate materials derived from ASTM F-1580 Standard. Values indicate maximum allowed content.

Note: PS, CS indicate plasma spray and cold spray processes, respectively 
Table 2: Selected physical and mechanical properties of Ti and Ti6Al4V

\begin{tabular}{llcc}
\hline Property & Unit & $\mathrm{Ti}$ & Ti6Al4V \\
\hline Density & $\mathrm{g} \cdot \mathrm{cm}^{-3}$ & 4.506 & 4.420 \\
Melting point & $\mathrm{K}$ & 1941 & 1886 \\
Thermal conductivity & $\mathrm{W} /(\mathrm{m} \cdot \mathrm{K})$ & 21.9 & 7.2 \\
Thermal expansion coefficient & $\mathrm{K}^{-1}$ & $8.6 \times 10^{-6}$ & $8.6 \times 10^{-6}$ \\
Elastic modulus & $\mathrm{GPa}$ & 116 & 114 \\
Tensile strength & $\mathrm{MPa}$ & 434 & 895 \\
Yield strength & $\mathrm{MPa}$ & 330 & 828 \\
\hline
\end{tabular}

Table 3: Spray parameters for plasma and cold spray coatings deposition

\begin{tabular}{lclc}
\hline Plasma spray parameters & \multicolumn{3}{c}{ Cold spray parameters } \\
\hline Net power & $15 \mathrm{~kW}$ & Pressure gas temperature & $533 \mathrm{~K}$ \\
Flow of main gas & $47.2 \mathrm{l} \cdot \mathrm{min}^{-1}$ & Working gas pressure & $1.67 \mathrm{MPa}$ \\
Flow of auxiliary gas & $37.8 \mathrm{l} \cdot \mathrm{min}^{-1}$ & & \\
Flow of carrier gas & $7.1 \mathrm{l} \cdot \mathrm{min}^{-1}$ & Feeder gas pressure & $1.72 \mathrm{MPa}$ \\
Hopper system revolutions & $4 \mathrm{rpm}$ & Feedrate frequency & $50 \mathrm{~Hz}$ \\
Spray distance & $120 \mathrm{~mm}$ & Spray distance & $12 \mathrm{~mm}$ \\
Robotic arm speed & $100 \mathrm{~mm} \cdot \mathrm{s}^{-1}$ & Robotic arm speed & $40 \mathrm{~mm} \cdot \mathrm{s}^{-1}$ \\
Number of passes & 30 & Number of passes & 2 \\
\hline
\end{tabular}


Table 4: Results of fatigue test and measured coating thicknesses and respective surface roughnesses of the specimens

\begin{tabular}{|c|c|c|c|c|c|c|c|c|}
\hline \multirow[t]{3}{*}{ Specin } & \multirow{3}{*}{ number } & \multirow{3}{*}{$\begin{array}{c}\text { Coating } \\
\text { thickness } \\
{[\mu \mathrm{m}]}\end{array}$} & \multirow{2}{*}{\multicolumn{2}{|c|}{$\begin{array}{c}\text { Surface } \\
\text { roughness }\end{array}$}} & \multirow{2}{*}{\multicolumn{2}{|c|}{$\begin{array}{c}\text { Fatigue life } \\
\text { [cycles] }\end{array}$}} & \multirow{3}{*}{$\begin{array}{c}\text { Resonance } \\
\text { frequency } \\
{[\mathrm{Hz}]}\end{array}$} & \multirow{3}{*}{$\begin{array}{c}\text { Relative } \\
\text { life } \\
R_{f}[1]\end{array}$} \\
\hline & & & & & & & & \\
\hline & & & $R_{a}[\mu m]$ & $R_{z}[\mu m]$ & & B & & \\
\hline \multirow{4}{*}{ As-received } & A1 & & & & 395511 & $*$ & 71.2 & \multirow{4}{*}{1.00} \\
\hline & A2 & & & & 327868 & 412437 & 72.1 & \\
\hline & A3 & & & & 506654 & 514967 & 71.2 & \\
\hline & A4 & & & & 494907 & 588302 & 71.2 & \\
\hline \multirow{3}{*}{ Grit-blasted } & G1 & & \multirow{3}{*}{2.92} & \multirow{3}{*}{12.97} & $*$ & $*$ & 71.2 & \multirow{3}{*}{1.81} \\
\hline & G2 & & & & 860375 & 899287 & 70.6 & \\
\hline & G3 & & & & 820399 & 775803 & 70.8 & \\
\hline \multirow{6}{*}{ Plasma sprayed } & $\mathrm{P} 1$ & \multirow{6}{*}{$871 \pm 5$} & \multirow{6}{*}{8.49} & \multirow{6}{*}{30.60} & 588502 & 541202 & 74.6 & \multirow{6}{*}{1.16} \\
\hline & $\mathrm{P} 2$ & & & & $*$ & $*$ & 77.9 & \\
\hline & P3 & & & & del. & del. & - & \\
\hline & $\mathrm{P} 4$ & & & & 593891 & 532716 & 76.8 & \\
\hline & P5 & & & & 544597 & 492007 & 76.8 & \\
\hline & P6 & & & & 465828 & $*$ & 76.3 & \\
\hline \multirow{6}{*}{ Cold sprayed } & $\mathrm{C} 1$ & \multirow{6}{*}{$650 \pm 17$} & \multirow{6}{*}{11.28} & \multirow{6}{*}{40.90} & $*$ & $*$ & - & \multirow{6}{*}{0.91} \\
\hline & $\mathrm{C} 2$ & & & & $*$ & 348530 & 83.9 & \\
\hline & $\mathrm{C} 3$ & & & & 345489 & $*$ & 84.3 & \\
\hline & $\mathrm{C} 4$ & & & & 443956 & 480991 & 84.8 & \\
\hline & C5 & & & & 379977 & 531687 & 84.3 & \\
\hline & C6 & & & & $*$ & del. & - & \\
\hline \multirow{2}{*}{ Delaminated } & P3 & $871 \pm 5$ & & & 990655 & 696342 & 72.0 & \multirow{2}{*}{1.80} \\
\hline & C6 & $650 \pm 17$ & & & 819163 & $*$ & 72.3 & \\
\hline
\end{tabular}

Note: Specimens marked * broke abnormally or were used for initial system PPL feedback calibration Specimens marked "del." experienced coating delamination during initial testing phases

Table 5: Elastic moduli and porosity of deposited coatings

\begin{tabular}{lcc}
\hline Material & Elastic modulus & Porosity \\
\hline Plasma sprayed Ti & $7.2 \mathrm{GPa}$ & $10.2 \%$ \\
Cold sprayed $\mathrm{Ti}$ & $36.7 \mathrm{GPa}$ & $0.5 \%$ \\
Bulk Ti & $116 \mathrm{GPa}$ & - \\
\hline
\end{tabular}

